\title{
VALUE CREATION FOR STAKEHOLDERS IN HIGHER EDUCATION MANAGEMENT
}

\author{
Jelena Stankevičienè, Agnè Vaiciukevičiūtè
}

\section{Introduction}

Traditional philosophy behind university and its capability to be prolific generally accent mostly known fields as teaching, research and service to the student as well as society. Evaluation of these fields in terms of its quality and efficiency encourage universities to allocate appropriate evaluation criteria (weights) in order to maintain consistency in performance process that follows all units within the university. Recently this notion became a normal precondition for ambitious universities that are willing to stay competitive. Furthermore, without measurable performance and criteria attributed, it becomes complicated to make proactive planning decisions ranging from funding new positions to optimizing unnecessary processes.

Questioning the contribution and value of higher education is relevant and widely discussed research area (McClung \& Werner, 2008; Tomosho, 2006; Turner, 1996). It is nothing new that in the century of market driven society stakeholders became more concerned of value created by universities. What is really new is the capacity to measure value, and with this proficiency, greater ability to manage it (McClung \& Werner, 2008). Furthermore, opponents would argue that there are not enough accurate methods to measure value created. Therefore, in this paper the new multicriteria Factor Relationship (FARE) method with relatively higher precision compared with Analytic Hierarchy Process (AHP) method will be implemented.

Within changes in Higher Education Institutions (HEls) environment which was accelerated by internationalization process it is nothing new that the importance to rethink the idea of what creates value for HEls nowadays became questioned by researchers more frequently (Vincent-Lancrin \& Pfotenhauer, 2012). What is really changed during the last decades it is apprehension that university will depend not only on its ability to create knowledge, but will be highly influenced by its potential 'customers' internationally with its capacity to be accountable enough for its stakeholders. Moreover, the trend to optimize everything what enhance so called 'productivity' in HEls management became not a choice but contrary, a necessity in order to remain.

However, while there is lots of literature due to value creation in HEls from the student or state perspective, one aspect is usually left behind. There is deficiency of knowledge in terms of value creation through university perspective. The task occurred to be complicated, because HEls delivers combined variety of benefits including both tangible and intangible, which can hardly be expressed through financial data. Furthermore, those types of benefits can occur (and usually do) over a time which makes it even harder to measure. Despite the actuality of the matter, we found only several papers (Pecht, 2008; Thornton, 2004; et. al.) where such attitude was discussed. Therefore, we think that deficiency of appropriate explanation and the lack of attention to this issue give us a wide range of possibilities to explore value creation process when a university is considered as beneficiary of value created.

In this particular paper the focus has been taken to look through multi-criteria Factor Relationship (FARE) (Ginevičius, 2011) method implementation at one of the Lithuanian universities were the main challenge was to assess appropriate Key Performance Indicators (KPIs) that covers two main aspects in value creation process: internationalisation (Brandenburg \& Federkeil, 2007) and employees as the most influential stakeholder group when value creation considered through university perspective. This choice was made due to the newest data availability. Therefore, 
the article will mainly concern with the first stage of higher education supplied by state-owned institutions, although calculations and method can be applied for any level, any institution type in case a required data is available.

\section{Stakeholders Role in University Management}

There is no secret that stakeholders' management is one of the most crucial aspects toward successful value creation process irrespectively of whether it is private or public sector. But the lack of research in the scope of $\mathrm{HEls}$ stakeholders management strategies and general perception of what added value each of them can generate, brought to the point where deeper analysis is required.

Within the context of HEls, The Stakeholder Theory (Financial Times LEXICON, 2011) more concentrates on explaining the linkage between educational institutions and the environment which affect the operation of the higher education institution. One of widely discussed definition of stakeholders can be described as 'individuals or groups who depend on an organisation to fulfil their own goals and on whom, in turn, the organisation depends' (Johnson et al., 2008).
Though, it is still very difficult to identify and classify types of stakeholders in HEls, because of diversity in classification methods. Therefore, the need to identify just who those stakeholder groups in HEls are arises (Mainardes et al., 2011). John Borwick (2013) built a high-level map of the system of US higher education by including all the external stakeholders involved in HEls and distinguished how they are related and interconnected within each other. With several adaptation and incorporation of internal stakeholders the map of higher education institution of stakeholders are represented below (Fig. 1).

The stakeholders' perspective above demonstrates organization in its environmental scope with interaction attributes. These linkages help to manage in and out operations through distribution channels and to perceive all the participants in the process of internal and external practices (Maric, 2013; Robbins et al., 2008). Thus, the importance to identify key stakeholders occurs in order to understand how much the variety of stakeholders have changed and what is the most important, how strongly these groups are related to each other.

\section{Fig. 1: Map and linkages of internal and external stakeholders groups in HEls}

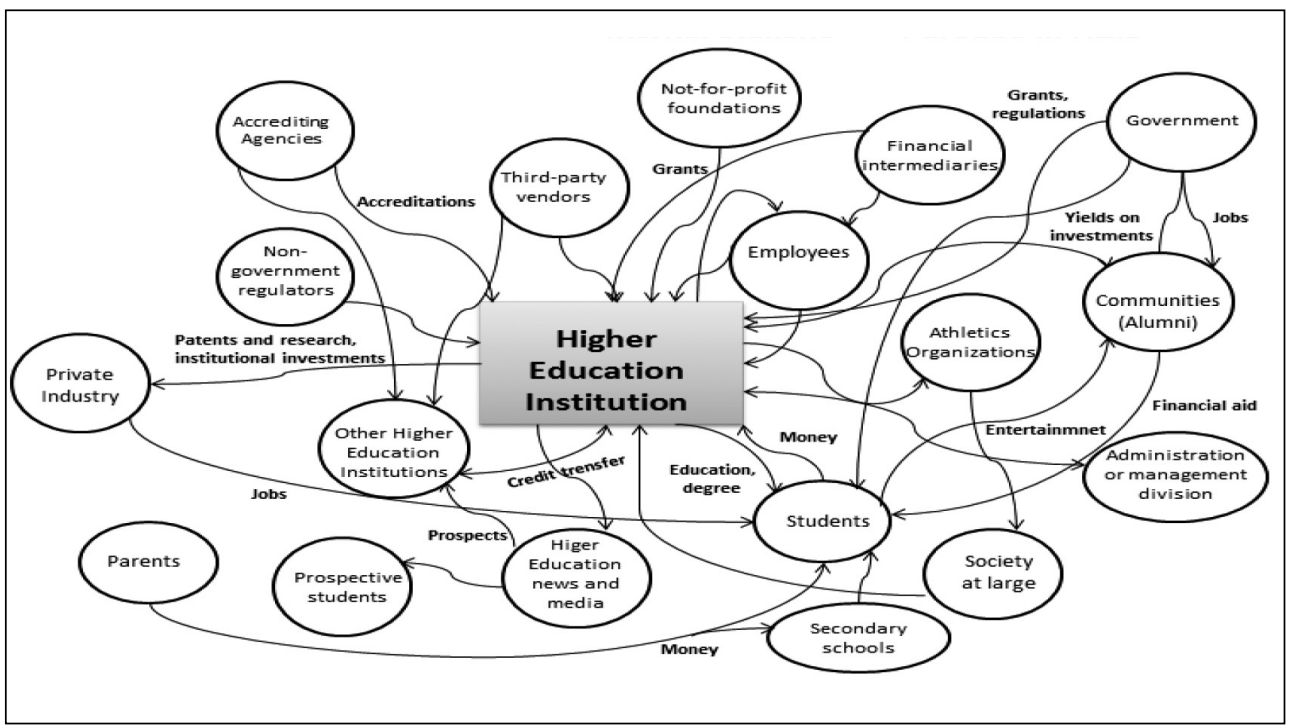

Source: authors insights and Borwick (2013) 


\begin{tabular}{l|l} 
Stakeholder category & \multicolumn{1}{c}{ Constitutive groups, clients, etc. } \\
\hline Government entities & $\begin{array}{l}\text { Government, boards of management and directors, sponsors and } \\
\text { buffer organisations. }\end{array}$ \\
\hline Administration or Management & Presidents, rectors, directors (all senior administrators). \\
\hline Employees Clients & Faculty, administrative and support personnel. \\
\hline Suppliers & $\begin{array}{l}\text { Students, parents, social financing entities, education providers, } \\
\text { service partners, insurance companies, alumni and food } \\
\text { purveyors. }\end{array}$ \\
\hline Competitors & $\begin{array}{l}\text { Direct: public and private higher education establishments. } \\
\text { Potential: distance providers; new ventures. Substitutes: } \\
\text { company training programmes. }\end{array}$ \\
\hline Donors & $\begin{array}{l}\text { Individual (including directors, friends, parents, former students, } \\
\text { employees,industry, research boards, foundations). }\end{array}$ \\
\hline Communities & Chambers of commerce, special interest group. \\
\hline Government regulators & $\begin{array}{l}\text { Ministry of education, support entities, state financing agencies, } \\
\text { research board. }\end{array}$ \\
\hline Non-governmental regulators & $\begin{array}{l}\text { Foundations, institutional and programmatic accrediting bodies, } \\
\text { professional associations. }\end{array}$ \\
\hline Financial intermediaries & Banks; fund managers, analysts. \\
\hline Joint venture & $\begin{array}{l}\text { Businesses, enterprises, employers, alliances \& consortia, } \\
\text { corporate, co-financiers of research and teaching services. }\end{array}$ \\
\hline
\end{tabular}

In the context of this paper, the most appropriate categorization of stakeholders was chosen. In table below (Tab. 1), specific categories of stakeholders that indicates a different pressure, influences reflected through actions, policies and the behaviour of each groups where distinguished.

Many authors (Dorri et al., 2012; Goldsworthy, 2008; Pathak \& Pathak, 2010; etc.) unanimously agree that academic operations in HEls are challenged by more versed and exacting customers, while at the same time trying to adjust the other two crucial customers as funding agencies and the ranking agencies with the aim to assure and generate national / international visibility and reliability. Therefore, beyond determining stakeholders of university, their particular needs and demands have to be ascertained. This notion was clarified by Bjorkquist (2008) when the demands and needs where distinct into three different groups: nonstudents, students as individuals and students with specific features. Each group has specific actors as professional entities and employers or student groups with specific characteristics in carefully defined services. However, one thing is clear that different ways to define stakeholders vary through several dimensions and depends on the specific issue organization once to deal with.

\subsection{Adapting Stakeholders to HEls (Power and Cooperation)}

In the current situation, when significance to encourage partnerships (internally and externally) grows exponentially, the critical factor to distinguish appropriate stakeholders according to the efficiency that they can provide becomes essential. Indeed, stakeholders play vital roles as partners, donors and agents of change. Many different authors have been writing about stakeholders in private sector, but the public sector still lags some proper implications and ways to look deeper (Ipsos MORI, 2009). Also, the majority of incentives 
to react in HEls concerning this issue arises coincidently and do not provide complex of knowledge of the issue itself. With this understanding, the need to analyse higher education institutions not as a whole, but specifically arises.

Generally speaking, there is lack of literature that would classify or in any way try to distinguish potential types of stakeholders in HEls according to the dimensions of power and cooperation. There is not enough attention to HEls management methods to deal with variety of stakeholders. This shortage became more visible now when pressure between different HEls management ways has been differentiated by financial resources (private, public, entrepreneur universities etc.) and increased choice of external stakeholders. From all variations of stakeholders there is important to capture most relevant once who could efficiently respond to the issues and challenges. Thus, it is worth to mention that the sensitivity to act highly depends on stakeholder's power and desire to cooperate in resolving existing situation or problems. Therefore, the need to categorize and differentiate stakeholders groups in HEls becomes the priority.

Dimensions according to business oriented organizations are recognized as threat and potential for collaboration (Savage et al., 1991). Due to public HEls management the potential to influence and create value, need to be adjusted (modified) more appropriately. Consequently, two dimensions of power and willingness to cooperate where chosen. According to those dimensions and selected groups (Tab. 1) four types (Fig. 2) of generic ways to manage stakeholders for HEls where distinguished and categorized in our chosen key study.

Based on the stakeholders' distribution the employees from the group with the highest power and cooperation level were chosen as a target group. This group is the closest to the management of the chosen university operations and has high power (compared with other stakeholders groups) to influence management decisions. In general, this group comprises of the employees resources of teaching and research, researchers, executives (including administration staff and those working

\section{Fig. 2: Typology of Stakeholders Groups in one of Lithuanian Universities}

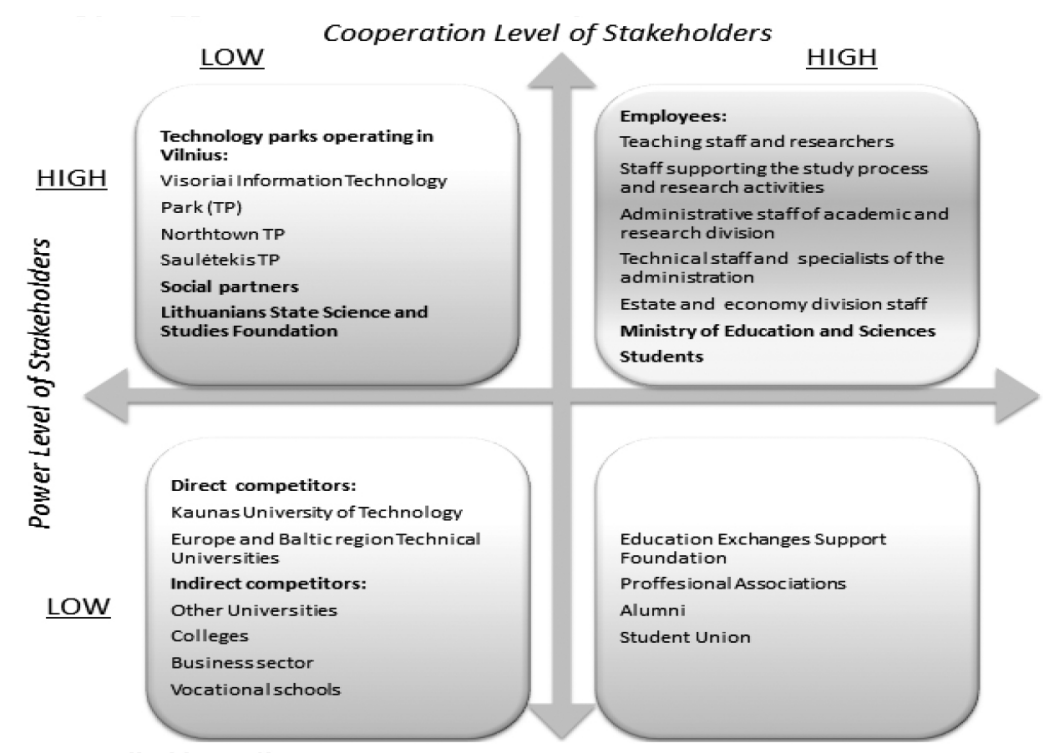

Source: compiled by authors 
at academic and research subdivisions), technical personnel of administration, staff assisting in providing studies, staff assisting in conducting research, and internal economy staff. Consequently, when the target stakeholder group was chosen the need to adjust the most appropriate Key Performance Indicators (KPIs) for employees' performance through internationalisation aspect became inevitable.

\subsection{KPls for Target Stakeholder Group}

The Key Performance Indicators (KPIs) is an essential part of accountability that helps organization to gauge and observe potential advancement. Thus, it helps to prioritize target goals according to budget constrains in a most diligent way. Consequently, the conditions such as international competition and financial restrictions lead to changes in performance management, especially measurement (Webber, 2003).

The international standards increase gradually by forcing HEls to adapt their measurement KPIs in pursuance to withstand the competition. Complex changes in rivalry have made universities to implement certain business-specific features. A number of different indicators have impelled the higher education sector to review its standpoint towards capacity to compete in such agile environment. HEls needed not only to come up with fresh ideas how to become much more competitive to engage and maintain students, but to decide which KPIs will lead to more effective decision support management system too. According to Ong, Muniandy (2013) KPIs is a fundamental concept in the area of performance management. But the problems which occurs here is the difficulty to define critical KPIs.

In the context of this paper we mainly focused on two types of KPIs groups related to employees and internationalization performance indicators. Those two groups where chosen because firstly, it is not a secret that employees and other staff require the largest cost in HEls management, so resource utilization revision remains crucial. Thus, productivity and efficiency is critical to the overall performance of the institution. Secondly, nowadays one of the most visible components which highly influence overall performance of employees as well as university is internationalization. Increased commercialization and cross-border competition have changed the value traditionally assumed to HEls to value generated through international partnerships and cooperation (Wit, 2009). Therefore, this aspect was chosen in order to see how employees' performance interacts with internationalization process and what kind of resources distribution proportion would give the highest value for institution which actively participates in international environment. In simplistic terms, the quality of the university performance is highly influenced by employees' performance quality which in turn, has a significant impact on the university value creation in the international scope.

Broadly speaking, the evaluation of any kind of higher education institution consists of three main key success factors (KSF) (Suryadi, 2007):

- Achievements in academic environment;

- Achievements of research quality;

- Achievement of community services, supporting activities and coherence with internationalization KPls effectiveness.

These KSFs then became the basis for measuring HEls performance. Based on the stakeholders' distribution (Fig. 2), the group of employees with the highest power and cooperation level has been chosen as a target group. These stakeholders were selected because they are closely related to the management of the university operations and have higher power to influence management decisions then others.

Based on the chosen criteria, the next step was to identify list of KPIs for employees related to this particular KSF. In order to be more realistic, the selected KPIs were adapted from the chosen key study Development strategy for 2014-2020 and the experts group of CUC (Committee of University Chairman) in collaboration with J. M. Consulting Ltd (2006) that refers to the responsibility of the executives to monitor institutional performance.

Based on the information gathered in those two documents, the most relevant KPIs which respond to components as employees and internationalisation were selected (Tab 2).

The employees of the university were compared against 6 criteria, 4 of which characterize specific performance of various types of employees based on internationality aspect which was considered as important component in overall performance, 1 refer to financial performance activities and another 
Tab. 2: KPIs for Employees through Internationalisation Aspect

KPIs for Employees

\begin{tabular}{l|l}
\hline 1. Employees Financial Conditions & 4.Young Researchers Internationality \\
\hline 2. Professors Internationality & $\begin{array}{l}\text { 5. Administrative Staff/ Non-Academic Staff } \\
\text { Conditions }\end{array}$ \\
\hline 3. Lecturers Internationality & $\begin{array}{l}\text { 6. Service and Administration Resources } \\
\text { Environment }\end{array}$ \\
\hline
\end{tabular}

Source: Brandenburg \& Federkeil (2007); CUC \& J M Consulting Ltd. (2006)

1 respond to resource contribution towards internationality in university as a whole. Based on these KPIs the calculations of how important each of represented criteria group with its sub-criterion in value creation process was calculated.

\section{FARE Method for Weights of KPIs Assessment}

The reliability of the results calculated by multicriteria evaluation methods mostly depends on how accurately the determination of the criteria weight was made. The main shortage of popular methods is when the number of criterion is large, because in that case the reliability of method significantly decreases. Therefore, the new Factor Relationship (FARE) method implemented by Ginevičius (2011) becomes an excellent counterbalance to solve this problem. The main idea behind the method is that in the first stage the minimum amount of initial data from experts is required and then, based on the conditions of functioning and the specific features of the complete set of criteria as well as the relationship between other criteria with their direction are identified analytically in concordance with at first stage data gathered (Ginevicius \& Podvezko, 2008). This means that even if there are larger amount of criteria the minimum amount of initial data allows to implement FARE method more widely in calculating weights for more criteria than using other methods.

The reliability of the method was compared with other popular multicriteria evaluation methods as Analytic Hierarchy Process (AHP) (Saaty, 1993), Ranking, Direct and Indirect experts' evaluation methods and accuracy was proved (Ginevicius, 2006). To use FARE method in value creation process for HEls the fallowing sequence of this method and actions needs to be made and explained (Ginevicius, 2011):

1. Firstly, there is a precondition: according to Systems Theory all subsets of a set and their elements should be connected in some way.

2. Secondly, there are two main rules to be considered:

a) When the number of criteria transferring their potential to the considered criterion increases, its total potential and the impact on the research object also increase.

b) When the number of the criteria transferring their potential to this criterion decreases, its total potential and the impact of the considered criterion on the research object also decrease.

Now it is possible to describe quantitatively the potential of the impact produced by a system's criterion on the research object. This would be the largest possible value of the criterion's impact, which depends on the number of system's criteria and the scale used for evaluating the relationship between the criteria (e.g. ten-point scale). Therefore the potential could be equal to:

$P=S(m-1)$,

where $P$ is the potential of the system's criterion impact; $S$ is the maximum value of the scale of evaluation used; $m$ is the number of the system's criteria.

3. The experts need to rank all the criteria in order to determine the relationships of the main criterion with other criteria.

4. Then, the experts should only determine the scope of the transfer by using (Tab. 2) 
for the highest rank criterion (the criterion of a lower rank has the smaller impact on the criteria having higher ranks and, therefore, it should transfer a larger part of its potential impact to them). To achieve this, the experts should determine the impact of the criteria on the main criterion:

$a_{1 i}=S-\widetilde{a_{1 i}}$,

where $a_{i}$ is the impact of $i$-th criterion on the first main criterion; $\widetilde{a_{1}}$ is the part of $i$-th criterion's potential impact transferred to the main criterion.

5. According to subjectivity of experts' evaluation the consistency between the judgments experts by using concordance coefficient of Kendall (Kendall, 1970) need to be revisited.

6. Then, based on some particular characteristics of interrelationships between the criteria the relations between the remaining criteria and their strength, in accordance with the relationships established at the first stage, are measured analytically.

7. Now the direction and strength of the relationship can be determined by using these two conditions:

a) To find the direction - the lower rank criterion always transfers a part of its potential to a higher rank criterion. Consequently the arrow direction goes from smaller rank to higher rank criterion.

b) To find the impact - the impact of strength to the relationship considered will always be equal to the difference between the impact strength of two other relationships of the subset, which are already known. The impact can be found by formula:

$$
\widetilde{a_{\imath}}= \pm\left(\widetilde{a_{11}}-\widetilde{a_{\imath 2}}\right)
$$

The matrix has a structure $a_{i j}=-a_{i j}$ where the row or column of the matrix demonstrates the total effect or dependence of a particular criterion on other criteria compared with it. In order to check if the set is completely consistent the sum of the total impact values of the individual system's criteria on the research object should be always equal to zero.

8. Then, the total potential impact $P_{i}$ can be calculated based on the data presented in the first row of the matrix, thereby making the filling of all other rows of the matrix unnecessary:

$$
\boldsymbol{P}_{\boldsymbol{i}}=\boldsymbol{P}_{\boldsymbol{i}}-m \cdot \boldsymbol{a}_{1 i}
$$

The total impact or dependence of a criterion shows its dominance over other criteria of the set.

9. Now the total impact of each criterion should be compared with the total potential $\left(P_{S}\right)$ of the effect of a set of criteria:

$$
\boldsymbol{P}_{\boldsymbol{S}}=m \cdot P=m S(m-1),
$$

10. When the indicator of potential impact $P$ is known, their actual potential in the considered system may be found:

$$
\boldsymbol{P}_{i}^{f}=\boldsymbol{P}_{i}+P,
$$

where $P_{i}^{f}$ is the actual total impact of the $i$-th criterion of the system on the research object; $P_{i}$ is the total impact produced by the i-th criterion of the system or its total dependence on other criteria.

11. Now, we can normalize the values $w_{i}$ of the potential of the total impact of the criteria on the research object and to calculate their weights:

$$
W_{i}=\frac{P_{i}^{f}}{P_{S}}=\frac{P_{1}-m a_{1 i}+S(m-1)}{m S(m-1)} .
$$

According to Ginevičius (2011) the criteria describing a particular object reflect its various facets. Simply speaking, it shows that all faces are interrelated within each other which means that weights of criteria can be calculated more precise if all the above relationships are taken into consideration. When the weights of any kind of research object is clear, optimization model of rational financial distribution for value creation can be adapted.

\section{Results Captured by FARE Method}

The precision of the results obtained by using multi-criteria evaluation method usually depends on the determination of the criteria weights which are based on their interrelationship with each other (Ginevicius, 2006). Therefore, FARE method was chosen as one of the most accurate at the moment. 
The experts (from all faculties: 10 Deans and 1 Vice-rector) who are closely related to decision making within the university. By interviewing experts were asked to estimate 6 key performance indicators groups. There were several reasons why such decision was made. Firstly, our research field was quite narrow and each of chosen criteria group had its own sub-criterion (in total 31) therefore, the need to expand the number of criteria groups appeared irrational because of potential decrease in accuracy of the results. Secondly, there can be limitations of statistical data on particular criterion therefore; the precision in selecting KPls should be optimal as much as it is possible.
First of all, the experts needed to rank all the criteria groups in order to determine the relationships within criteria (Tab. 3). Based on the logic of our chosen criteria number 6 the ranking amplitude from 1 to 6 was established, where 1 was the highest influence indicator and contrary 6 was the lowest. That means that, the criterion which was ranked as first has the highest influence on overall value creation process for university in comparison with others.

Then, the experts needed only to determine the scope of the transfer (Tab. 5) for the highest rank criterion. This was done by using the scale of quantitative evaluation of interrelationship between the system's criteria represented below (Tab. 4):

Tab. 3: The ranks of system's criteria groups assigned by experts

\begin{tabular}{l|l|l|l|l|l|l} 
Criterion group & $\mathbf{1}$ & $\mathbf{2}$ & $\mathbf{3}$ & $\mathbf{4}$ & $\mathbf{5}$ & $\mathbf{6}$ \\
\hline Rank & 6 & 2 & 3 & 4 & 5 & 1 \\
\hline
\end{tabular}

Source: assigned by experts

\begin{tabular}{c|c|c} 
Tab. 4: & \multicolumn{2}{l}{$\begin{array}{l}\text { The scale of quantitative evaluation of interrelationship between the system's } \\
\text { criteria }\end{array}$} \\
No. & Type of the Effect Produced & $\begin{array}{c}\text { Rating of the Effect Produced by Inte- } \\
\text { rrelationship (in Points) }\end{array}$ \\
\hline 1 & Almost none & 1 \\
\hline 2 & Very weak & 2 \\
\hline 3 & Weak & 3 \\
\hline 4 & Lower than average & 4 \\
\hline 5 & Average & 5 \\
\hline 6 & Higher than average & 6 \\
\hline 7 & Strong & 7 \\
\hline 8 & Very strong & 8 \\
\hline 9 & Almost absolute & 9 \\
\hline 10 & Absolute & 10 \\
\hline
\end{tabular}

Source: Ginevicius (2011)

Tab. 5: The relationship between the six main criterion group and other system's criteria determined by the experts

\begin{tabular}{c|c|c|c|c|c|c} 
Criteria & $\mathbf{6}$ & $\mathbf{2}$ & $\mathbf{3}$ & $\mathbf{4}$ & $\mathbf{5}$ & $\mathbf{1}$ \\
\hline 6 & & +9 & +8 & +6 & +4 & +3 \\
\hline
\end{tabular}




\begin{tabular}{c|c|c|c|c|c|c} 
Criteria & $\mathbf{6}$ & $\mathbf{2}$ & $\mathbf{3}$ & $\mathbf{4}$ & $\mathbf{5}$ & $\mathbf{1}$ \\
\hline 6 & & +1 & +2 & +4 & +6 & +7 \\
\hline
\end{tabular}

Source: compiled by authors

The meaning behind this ranking is that the criterion of a lower rank has the smaller impact on the criteria having higher ranks. That is why it should transfer a larger part of its potential impact to them. It follows that the ranks of the calculated criteria weights should match their numbers in the priority list. This knowledge will help us in further calculations to determine the strength and direction within relationship between criteria.

When we have determined relationship between the main criterion (in our case it is 6th criterion), the concordance coefficient of Kendall (1970) was calculated which showed the sufficient consistency of experts evaluations. The idea of concordance coefficient was to revisit compatibility of the results. The data was primary converted into ranks; later the ranks were displayed, and finally calculated.

Now we were able to analytically measure the relations between the remaining criteria groups and their strength, in accordance with the relationships established at the first stage. Based on the formula (2), the part of the criterion's potential impact was transferred to the first criterion (Tab. 6).

Thus, in the figure (Fig. 3) below can be seen that a criterion of the higher rank took a part of the lower rank criterion's potential, because the criterion of a lower rank has the smaller impact on the criteria having higher ranks so; it should transfer a larger part of its potential impact to them. Simply speaking, the experts determined that criteria 4 were ranked by number +6 which means that the effect on our main criterion 6 from criteria 4 is higher than average. Therefore, criteria 4 should transfer only potential impact equal to +4 .

As shown in table (Tab. 6), the first criterion is ranked sixth, while the second criterion is ranked second. It follows that the first criterion should transfer a part of the potential of its impact to the second criterion. This is confirmed in the figure (Fig. 4) below where based on this idea all relationship with the direction of the relationships and strength of the impact was calculated.

\section{Fig. 3: The relationship between the main (sixth) criterion and other system's criteria}

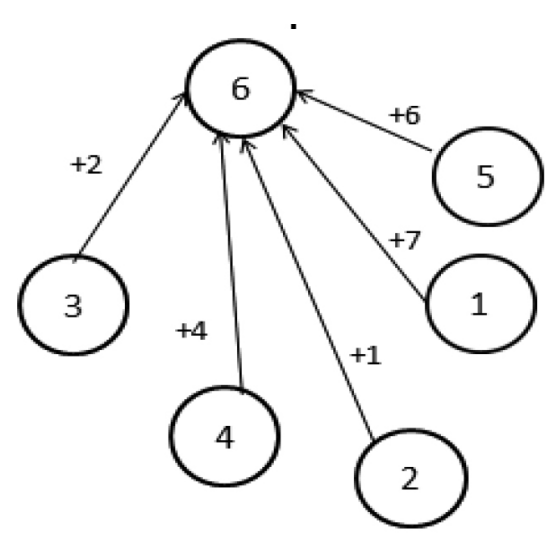


Fig. 4: The direction of the relationships and strength of the impact

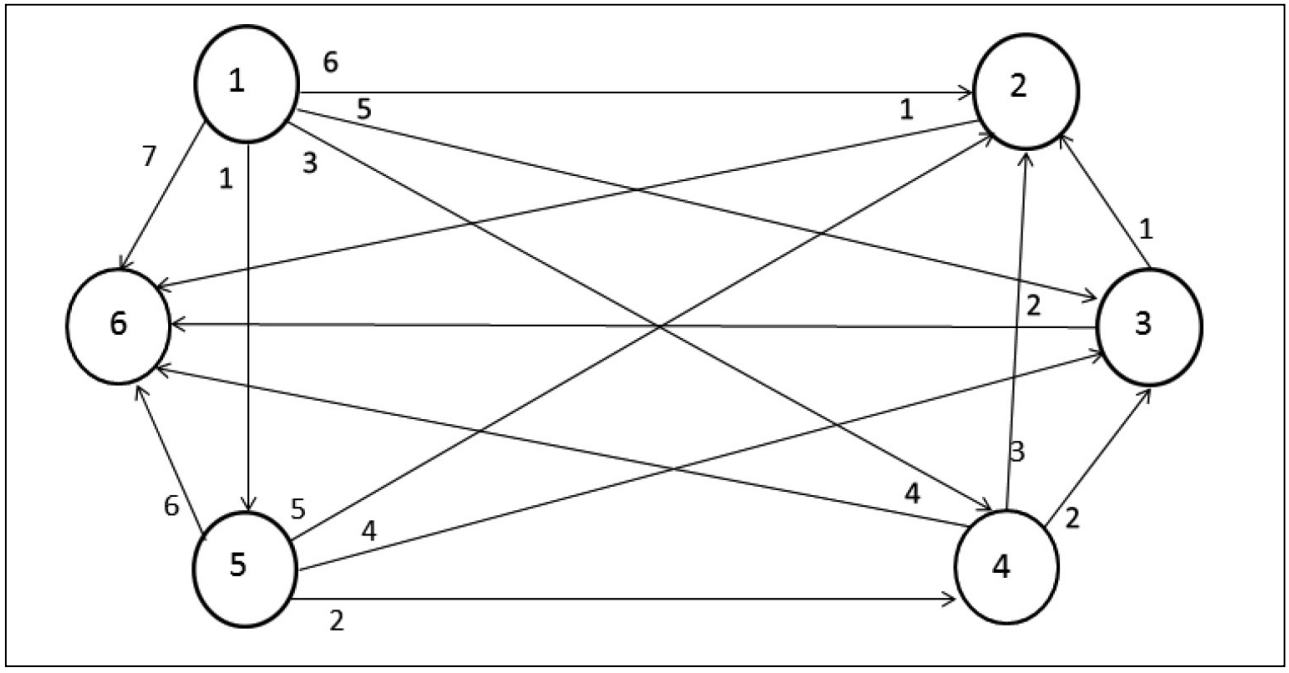

Source: compiled by authors

The direction is denoted by a plus or a minus; showing that the criterion considered either influences another system's criterion or depends on it. A negative relationship shows that the criterion considered is less significant than the criterion to which it is related. Therefore, it transfers a part of its potential to it. When it is positive, the considered criterion accumulates the potential of another criterion, thereby increasing the potential of its impact. Then, the matrix based on calculations gathered from figure (Fig. 4) above was calculated and represented in table with a summary matrix of the potential equilibrium (Tab. 7 ):

When we have the entire matrix, the total potential impact by using formula (4) was calculated based on the data presented in the first row of the matrix. The results can be seen in the table (Tab. 8) below. As can be seen the total effect (dependence) should be equal to zero which means that the results are compatible with each other.

Now in order to calculate weights based on formula (5) and formula (6) the actual total impact with the actual total impact of each criterion of the system on the research object were found:

Finally based on formula (7) the normalized values of the potential of the total impact of the criteria on the research object were calculated. Firstly for main criterion 6 , the results are represented in table below (Tab. 9) and then consequently, for all other criteria groups in the created matrix (Tab. 10).

There can be seen distribution of total effectiveness in each criteria group concerning employees' performance in value creation process.

KPIs for one of Lithuanian universities employees' performance with calculated weights for 6 criteria groups and extracted sub-criteria groups is represented in table below (Tab. 11). There is a need to take into account that weights were calculated for the group of criteria and then the authors relevantly distributed calculated weights to its subcriterions based on the financial data gathered from the university authorities.

\section{Conclusions}

Value in Higher Education Institutions is usually explained as benefit obtained from an institution's assets by its stakeholders. Academic and administrative staff, students and other related sides receives value through experiencing the institution's programmes, services and knowledge assets. It supports 


\section{Tab. 7:}

A summary matrix of the potential equilibrium of the criteria describing the research object

\begin{tabular}{c|c|c|c|c|c|c}
\multirow{2}{*}{ Criteria group } & \multicolumn{7}{|c}{ Criteria group } \\
\cline { 2 - 7 } & $\mathbf{1}$ & $\mathbf{2}$ & $\mathbf{3}$ & $\mathbf{4}$ & $\mathbf{5}$ & $\mathbf{6}$ \\
\hline $\mathbf{1}$ & & -6 & -5 & -3 & -1 & -7 \\
\hline $\mathbf{2}$ & +6 & & +1 & +3 & +5 & -1 \\
\hline $\mathbf{3}$ & +5 & -1 & & +2 & +4 & -2 \\
\hline $\mathbf{4}$ & +3 & -3 & -2 & & +2 & -4 \\
\hline $\mathbf{5}$ & +1 & -5 & -4 & -2 & & -6 \\
\hline $\mathbf{6}$ & +7 & +1 & +2 & +4 & +6 & \\
\hline Total & +22 & -14 & -8 & +4 & +16 & -20 \\
\hline
\end{tabular}

Source: calculated by authors

Tab. 8: The results obtained in calculating the total effect (dependence) of the criteria describing the research object

\begin{tabular}{|c|c|c|c|c|c|c|c|c|}
\hline \multirow[b]{2}{*}{ Criteria group } & \multicolumn{6}{|c|}{ Criteria group } & \multirow{2}{*}{$\begin{array}{c}\text { Total Effect } \\
\text { (Dependence) } \\
P_{i}\end{array}$} & \multirow[b]{2}{*}{$P_{i}^{f}$} \\
\hline & 1 & 2 & 3 & 4 & 5 & 6 & & \\
\hline 1 & & -6 & -5 & -3 & -1 & -7 & -22 & +28 \\
\hline 2 & +6 & & +1 & +3 & +5 & -1 & +14 & +64 \\
\hline 3 & +5 & -1 & & +2 & +4 & -2 & +8 & +58 \\
\hline 4 & +3 & -3 & -2 & & +2 & -4 & -4 & +46 \\
\hline 5 & +1 & -5 & -4 & -2 & & -6 & -16 & +34 \\
\hline 6 & +7 & +1 & +2 & +4 & +6 & & +20 & +70 \\
\hline Total & +22 & -14 & -8 & +4 & +16 & -20 & 0 & 300 \\
\hline
\end{tabular}

Source: calculated by authors

Tab. 9: The results of weight calculation of the criteria describing the research object

\begin{tabular}{l|c|c|c|c|c|c|c}
\multicolumn{1}{c|}{ Criteria group } & $\mathbf{1}$ & $\mathbf{2}$ & $\mathbf{3}$ & $\mathbf{4}$ & $\mathbf{5}$ & $\mathbf{6}$ & Total \\
\hline $\begin{array}{l}\text { The relationship between the } \\
\text { main (sixth) criterion with other } \\
\text { system's criteria }\end{array}$ & +7 & +1 & +2 & +4 & +5 & & $P_{1}=20$ \\
\hline $\begin{array}{l}\text { Weights of criteria group } \\
\boldsymbol{w}_{\boldsymbol{i}}\end{array}$ & 0.09 & 0.22 & 0.19 & 0.15 & 0.11 & 0.24 & $\begin{array}{l}\sum_{\mathbf{i}}^{\mathbf{w}_{\mathbf{i}}} \\
=\mathbf{1 . 0}\end{array}$ \\
\hline
\end{tabular}




\section{Ekonomika a management}

\begin{tabular}{|c|c|c|c|c|c|c|c|c|c|}
\hline \multirow{3}{*}{$\begin{array}{l}\text { Criteria } \\
\text { group }\end{array}$} & \multicolumn{9}{|c|}{$\begin{array}{l}\text { The calculation of the criteria weights of employees effectiveness by FARE } \\
\text { Method }\end{array}$} \\
\hline & \multicolumn{6}{|c|}{ Criteria group } & \multirow{2}{*}{$\begin{array}{c}\text { Total Effect } \\
\text { (Dependence) } \\
P_{i}\end{array}$} & \multirow{2}{*}{$\boldsymbol{P}_{i}^{f}$} & \multirow[b]{2}{*}{$w_{i}$} \\
\hline & 1 & 2 & 3 & 4 & 5 & 6 & & & \\
\hline 1 & & -6 & -5 & -3 & -1 & -7 & -22 & +28 & 0,09 \\
\hline 2 & +6 & & +1 & +3 & +5 & -1 & +14 & +64 & 0,22 \\
\hline 3 & +5 & -1 & & +2 & +4 & -2 & +8 & +58 & 0,19 \\
\hline 4 & +3 & -3 & -2 & & +2 & -4 & -4 & +46 & 0,15 \\
\hline 5 & +1 & -5 & -4 & -2 & & -6 & -16 & +34 & 0,11 \\
\hline 6 & +7 & +1 & +2 & +4 & +6 & & +20 & +70 & 0,24 \\
\hline Total & +22 & -14 & -8 & +4 & +16 & -20 & 0 & 300 & 1 \\
\hline
\end{tabular}

Source: calculated by authors

Tab. 11:

KPIs for one of Lithuanian universities employees with calculated weight (Part 1)

\section{Criteria Groups with Sub-criterion}

I. Employees Financial Conditions

Cost of staff as \% of total costs

Staff age, skills and diversity profile

Expenditure on staff development and training

Average Salary and Benefits

Staff satisfaction

Teaching/Research balance - income balance; TRAC data on staff effort, and surplus/deficit on $T$ and $R$

II. Professors Internationality
Calculated weights by FARE method

Number of professors having spent at least 1 study semester abroad

Percentage of business trips professors have taken abroad relative to the total number of professors

Number of professors who have acquired a doctoral degree abroad

Percentage of professors with professional experience abroad

\begin{tabular}{c|c|c}
$\begin{array}{c}\text { Unit } \\
\text { of measure }\end{array}$ & $\begin{array}{c}\text { Value } \\
\text { average }\end{array}$ & $\begin{array}{c}\text { Calculated } \\
\text { weights by } \\
\text { FARE method }\end{array}$ \\
\hline
\end{tabular}

\section{Lecturer Internationality}

0.19

Proportion of lecturers who teach technical disciplines in a foreign language

Percentage of lecturers who have spent at least 1 semester abroad

Percentage of lecturers who have held a visiting lectureship abroad in 2012

\begin{tabular}{|c|c|c|}
\hline In $\%$ & 70.8 & 0.02 \\
\hline In units & 44.2 & 0.01 \\
\hline Thous. Lt & 5,652 & 0.01 \\
\hline Thous. Lt & 2.5 & 0.03 \\
\hline In units & N/A & 0.01 \\
\hline Thous. Lt & N/A & 0.01 \\
\hline
\end{tabular}

\begin{tabular}{|c|c|c|c|} 
& In units & N/A & 0.02 \\
\hline In $\%$ & 20 & 0.08 \\
\hline In units & N/A & 0.02 \\
\hline
\end{tabular}




\begin{tabular}{|c|c|c|c|}
\hline Criteria Groups with Sub-criterion & $\begin{array}{c}\text { Unit } \\
\text { of measure }\end{array}$ & $\begin{array}{l}\text { Value ave- } \\
\text { rage }\end{array}$ & $\begin{array}{l}\text { Calculated } \\
\text { weights by } \\
\text { FARE method }\end{array}$ \\
\hline $\begin{array}{l}\text { Percentage of lecturers who gained their doctoral } \\
\text { degree abroad }\end{array}$ & $\ln \%$ & N/A & 0.01 \\
\hline Number of lecturers with international work experience & In units & 337 & 0.03 \\
\hline $\begin{array}{l}\text { Proportion of lecturers with international work } \\
\text { experience relative to the total number of lecturers }\end{array}$ & $\ln \%$ & 39 & 0.07 \\
\hline \multicolumn{3}{|l|}{ IV. Young Researchers Internationality } & \multirow[t]{2}{*}{0.15} \\
\hline $\begin{array}{l}\text { Number of young researchers who gained their } \\
\text { degree abroad (without doctorate) }\end{array}$ & In units & N/A & \\
\hline $\begin{array}{l}\text { Present proportion of young researchers who gained } \\
\text { their degree abroad (without doctorate) relative to the } \\
\text { total number of young researchers }\end{array}$ & $\ln \%$ & N/A & 0.03 \\
\hline $\begin{array}{l}\text { Number of young researchers who gained their } \\
\text { doctoral degree abroad }\end{array}$ & In units & N/A & 0.03 \\
\hline $\begin{array}{l}\text { Number of young researchers with post-doctoral } \\
\text { research periods (minimum duration?) abroad }\end{array}$ & In units & 5.6 & 0.03 \\
\hline $\begin{array}{l}\text { Total number of young researchers who have gained } \\
\text { at least one university degree abroad (Bachelor, } \\
\text { Master, PhD) }\end{array}$ & In units & $\mathrm{N} / \mathrm{A}$ & 0.03 \\
\hline \multicolumn{3}{|c|}{ V. Administrative Staff/ Non-Academic Staff Conditions } & 0.11 \\
\hline $\begin{array}{l}\text { Number of staff with foreign language skills as } \\
\text { a precondition for employment (including secretaries) }\end{array}$ & In units & $\mathrm{N} / \mathrm{A}$ & 0.01 \\
\hline $\begin{array}{l}\text { Number of staff who have taken part in international } \\
\text { administration exchange programmes in } 2012\end{array}$ & In units & 86 & 0.03 \\
\hline $\begin{array}{l}\text { Proportion of non-academic staff/ administrative staff } \\
\text { who have taken part in international administration } \\
\text { exchange programmes relative to the total number of } \\
\text { administrative staff }\end{array}$ & $\ln \%$ & 38.7 & 0.07 \\
\hline
\end{tabular}

\section{Service and Administration Resources Environment}

Administrative posts in the university for mentoring international students, doctoral candidates and visiting lecturers in relation to the total number of students (per faculty)

Internationally-oriented Career

Number of international professional qualification offers with or without credit points in relation to the total number of students

University budget for international cooperation Proportion of the budget for international cooperation in relation to the total budget

Number of posts (full time equivalent=FTE) for counselling on international applications (e.g. EU projects, double degrees etc.)

\begin{tabular}{c|c|c}
\hline In units & 28 & 0.07 \\
\hline Yes/No & Yes & 0.02 \\
\hline In units & 15 & 0.02 \\
\hline Thous. Lt & 6000 & 0.06 \\
\hline In \% & 4.8 & 0.05 \\
\hline In units & 13 & 0.02 \\
\hline
\end{tabular}


the notion that the most important part when creating value in HEls is efficient and productive resource management that starts with identifying essential stakeholders groups and attributing the most relevant Key Performance Indicators (KPIs) in order to measure performance.

In the context of this paper the target stakeholder group of employees where distinguished based on the created Typology Model which was adapted to the one of Lithuanian universities. It can be seen that university stakeholders appears in different types of classification that is strongly linked within university goals. Based on the chosen research perspective (public university as a beneficiary of value created) the most appropriate KPIs were chosen in accordance with target stakeholder group of employees and its coherency with greater internationalization and more efficient employees' resource management.

For the distinguished KPIs, the Factor Relationship (FARE) method was implemented in order to see how each of criteria group influences the overall performance (KPIs importance level). The results showed that the most important criteria groups were professors' internationality as well as Service and Administration Resources Environment. These two components had the highest importance weights compared with other criteria groups.

The internationality of professors and the importance of their involvement in internationalization process are exceptional, because of the visibility of indicators according to which the body of professors can be estimated in the scope of internationality. Furthermore, there is an opinion that service environment without internationally-oriented administration to succeed internationality would be almost impossible.

\section{References}

Alves, H., Mainardes, E.W., \& Raposo, M. (2010). A relationship approach to higher education institution stakeholder management. Tertiary Education and Management, 16(3), 159-181. doi:10.1080/13583883.2010.497314.

Bjorkquist, C. (2008). Continuity and change in stakeholder influence: reflections on elaboration of stakeholder regimes. Reflecting Education, 4(2), 24-38.

Brandenburg, U., \& Federkeil, G. (2007). How to Measure Internationality and Internationalisation of Higher Education Institutions! Indicators and Key Figures (Working Paper No. 92). Gütersloh: Centre for Higher Education Development [CHE]. Retrieved from: http://www.che.de/downloads/ How_to_measure_internationality_AP_92.pdf.

Borwick, J. (2013, September 19). Mapping the system of US higher education. HEIT Management. Retrieved November 25, 2013, from http://www.heitmanagement. com/blog/2013/09/mapping-the-system-of-ushigher-education/.

CUC in collaboration with $\mathrm{J} \mathrm{M}$ Consulting Ltd. (2006). CUC Report on the Monitoring of Institutional Performance and the Use of Key Performance Indicators. Sheffield: The University of Sheffield.

Dorri, M., Yarmohammadian, M.H., \& Nadi, M.A. (2012). A Review on Value Chain in Higher Education. Procedia-Social and Behavioral Sciences, 46, 3842-3846. doi:10.1016/j. sbspro.2012.06.157.

Financial Times LEXICON. (2011). Definition of stakeholder theory. In Financial Times LEXICON. Retrieved October 23, 2013, from http://lexicon.ft.com/Term?term=stakeholdertheory.

Ginevičius, R. (2011). A new determining method for the criteria weights in multicriteria evaluation. International Journal of Information Technology \& Decision Making, 10(6), 10671095. doi:10.1142/S0219622011004713.

Ginevicius, R., Podvezko, V. (2008). A feasibility study of multicriteria methods' application to quantitative evaluation of social phenomena. Business: theory and practice, 9(2), 81-87. doi:10.3846/1648-0627.2008.9.81-87.

Ginevičius, R. (2006a). A comparative analysis of multicriteria evaluation methods AHP and FARE used to determine the criteria weights. In 4th International Scientific Conference BUSINESS AND MANAGEMENT (pp. 16-18). Vilnius: Vilnius Gediminas Technical University.

Ginevičius, R. (2006b). Multicriteria Evaluation of the Criteria Weights Based on their Interrelationship. Business: theory and practice, 7(1), 3-13. doi:10.3846/btp.2006.01.

Goldsworthy, J. (2008). Research Grants mania. Australian Universities Review, 50(2), 17-24.

Ipsos MORI. (2009). Understanding your stakeholders. A best practice guide for the public sector. London: Ipsos MORI, Social 
Research Institute. Retrieved from https://www. ipsos-mori.com/Assets/Docs/Publications/sriunderstanding-stakeholders-november-2009. pdf.

Johnson, G., Scholes, K., \& Whittington, R. (2008). Exploring corporate strategy: text and cases. Harlow: Pearson Education.

Jongbloed, B., Enders, J., \& Salerno, C. (2008). Higher education and its communities: Interconnections, Interdependencies and Reaserch Agenda. Higher Education, 56(3), 303-324. doi:10.1007/s10734-008-9128-2.

Kendall, M.G. (1970). Rank correlation methods. London: Charles griffin.

Maric, I. (2013). Stakeholder Analysis of Higher Education Institutions. Interdisciplinary Description of Complex Systems, 11(2), 217226. doi:10.7906/indecs.11.2.4.

Mainardes, E., Alves, H., Raposo, M. (2011). Identifying Stakeholders in a Portuguese university: a case study. Revista de educación, 362 , 429-457. doi:10.4438/1988-592XRE-2012-362-167.

McClung, G.W., Werner, M.W. (2008). A Market/Value Based Approach to Satisfy Stakeholders of Higher Education. Journal of Marketing for Higher Education, 18(1), 102123. doi:10.1080/08841240802100345.

Ong, M.Y., Muniandy, B. et al. (2013). User Acceptance of Key Performance Indicators Management Systems in a Higher Education Institution in Malaysia: A Pilot Study. International Online Journal of Educational Sciences, 5(1), 22-31.

Pathak, V., \& Pathak, K. (2010). Reconfiguring the higher education value chain. Management in Education, 24(4), 167171. doi:10.1177/0892020610376791.

Pecht, J. (2008). Managing Limited Resources in Higher Education (Quality Endeavors Issue No. 107). University Park, PA: Pennsylvania State University. Retrieved from http://www.opia.psu.edu/features/lssue107.

Robbins, S., Bergman, R., \& Stagg, I. (2008). Management. Pearson Education Australia.

Saaty, T. (1993). Decision-Making. Analytic Hierarchy Process.

Savage, G.T. et al. (1991). Strategies for assessing and managing and managing stakeholders. Academy of Management Executive, 5(2), 61-75. doi:10.5465/ AME.1991.4274682.

Suryadi, K. (2007). Framework of Measuring Key Performance Indicators for Decision Support in Higher Education Institution. Journal of Applied Sciences Research, 3(12), 16891695.

Thornton, R. (2004). How Does a University Create Value? In 'Reinventing the University', Conference on Higher Education. Grahamstown, South Africa: Rhodes University.

Tomosho, R. (2006, Oct 25). As tuition soars, federal aid to college students falls. The Wall Street Journal, pp. B1-B2.

Turner, F.M. (1996). The idea of a university, John Henry Newman. NY: Vail-Ballou Press.

Vincent-Lancrin, S., \& Pfotenhauer, S. (2012). Guidelines for Quality Provision in Cross-border Higher Education: Where do we stand? (Education Working Paper Series). Paris: OECD. doi:10.1787/5k9fd0kz0j6b-en.

Webber, G. (2003). Funding in UK universities: living at the edge. Perspectives: Policy \& Practice in Higher Education, 7(4), 9397. doi:10.1080/1360310032000129441.

Wit, H. de (2009). Internationalization of Higher Education in Europe and its Assessment Trends and Issues. Den Haag: Nederlands-Vlaamse Accreditatieorganisatie [NVAO]. Retrieved from: http://nvao.com/page/ downloads/Internationalisation_of_Higher Education_in_Europe_DEF_december_2010.pdf.

Prof. Dr. Jelena Stankevičienè

Vilnius Gediminas Technical University Business Management Faculty Department of Finance Engineering jelena.stankeviciene@vgtu.It

Agnè Vaiciukevičiūtè, PhD

Vilnius Gediminas Technical University Business Management Faculty Department of International Economics and Business Management agne.vaiciukeviciute@vgtu.com 


\title{
Abstract
}

\section{VALUE CREATION FOR STAKEHOLDERS IN HIGHER EDUCATION MANAGEMENT}

\author{
Jelena Stankevičienè, Agnè Vaiciukevičiūtè
}

The article deals with value creation measurement issue in public Higher Education Institutions (HEIs) and discuss the linkage between selected Key Performance Indicators (KPIs) and new multicriteria Factor Relationship (FARE) method capability to present accurate results when one of the Lithuanian universities is chosen. In order to enhance the precision of the results, the specific stakeholder group according to their power and willingness to cooperate was used as the basis for selected KPIs. Based on the stakeholders' distribution the employees from the group with the highest power and cooperation level were chosen as a target group. The selection process was diverted to the criteria groups of efficiency and internationality regarding to value creation process when public university is considered as a beneficiary of value created. The employees of the university were compared against 6 criteria, 4 of which characterize specific performance of various types of employees based on internationality aspect which was considered as important component in overall performance, 1 refer to financial performance activities and another 1 respond to resource contribution towards internationality in university as a whole. The minimum amount of initial data of the relationship between the chosen criteria group was taken from experts and used as the basis for analytical evaluation of other criteria groups' relationship. Based on the new Factor Relationship (FARE) multi-criteria evaluation method, results concerning importance of each criterion were measured. The findings showed which KPls group plays the highest role in value creation process of selected Lithuanian university. The results showed that the most important criteria groups were professors' internationality as well as Service and Administration Resources Environment. These two components had the highest importance weights compared with other criteria groups.

Key Words: Value creation, higher education institution, stakeholder, key performance indicator, criterion weight, FARE method.

JEL Classification: G34, M12.

DOI: 10.15240/tul/001/2016-1-002 